\title{
AMS RADIOCARBON DATING OF BONE SAMPLES FROM THE XINZHAI SITE IN CHINA
}

\author{
Kexin Liu ${ }^{1,2} \cdot$ Baoxi $\operatorname{Han}^{1} \cdot$ Zhiyu Guo $^{1} \cdot$ Xiaohong $\mathrm{Wu}^{3} \cdot$ Sixun Yuan $^{3} \cdot$ Walter Kutschera ${ }^{4}$ \\ Hongji $\mathrm{Ma}^{1} \bullet$ Alfred Priller ${ }^{4} \cdot$ Peter Steier $^{4} \bullet$ Eva Maria Wild ${ }^{4}$ Chunqing Zhao ${ }^{3}$
}

\begin{abstract}
Xinzhai is an important archaeological site discovered $40 \mathrm{yr}$ ago and recently re-excavated in the Henan Province, China. It is believed that the cultural characteristics of the Xinzhai site correspond to the Xia dynasty, the first ancient dynasty of China. Radiocarbon measurements on bone samples from this site were performed at the Peking University AMS facility (PKU-AMS) and the Vienna University AMS facility (VERA). Calibrated ages were obtained with the computer program OxCal. The results of these measurements are presented and the related chronology is discussed.
\end{abstract}

\section{INTRODUCTION}

It is well known that Xia was the first ancient dynasty of China. This was recorded in the famous ancient book Shiji and in other literature, but there was no exact chronology given in those books and the authors gave different estimations of the chronology. Therefore, radiocarbon measurements and calibrations of samples from related sites become more important for investigating the chronological frame of the Xia dynasty.

From 1999 to 2000, the Xinzhai site in Henan Province, China, was excavated by the College of Archaeology and Museology, Peking University, and the Henan Archaeology Institute. The cultural remains of this site are plentiful and very significant for studying the cultural characteristics of the $\mathrm{Xia}$ dynasty. Serial bone samples have been collected from this site for ${ }^{14} \mathrm{C}$ analysis. ${ }^{14} \mathrm{C}$ measurements were performed at the Peking University AMS facility (PKU-AMS) and the Vienna University AMS facility (VERA). This paper describes the importance of the Xinzhai site, its ${ }^{14} \mathrm{C}$ sample measurements and age calibration, and subsequent discussions regarding the Xia chronology.

\section{XINZHAI SITE}

The Xinzhai site encompasses a total area of about $700,000 \mathrm{~m}^{2}$ and is located near Xinmi City in Henan Province, China. It was discovered in the 1960s and a systematic excavation was carried out until 1999. More than 100 hoards, ash pits, and tombs have been discovered and about 300 pottery wares have been unearthed and restored. Many bone samples have also been collected for ${ }^{14} \mathrm{C}$ analysis.

Excavation of the Xinzhai site is very important for archaeological research of the Xia dynasty. Before the excavation of the Xinzhai site, several sites related to the Xia dynasty were excavated and the remains from those sites were identified according to 2 cultural types: Erlitou culture and Longshan culture. The Erlitou site, located near Yanshi City in Henan Province, is a typical Erlitou culture site, and the Wangchenggang site, near Dengfen City, also in Henan Province, is exemplary of the Longshan culture. Archaeological research and ${ }^{14} \mathrm{C}$ analyses showed that the Longshan culture preceded the Erlitou culture and the transition between these 2 cultures was not continuous. Many archaeologists believe that the transition is evident in the remains found at the Xinzhai site and thus can be named the Xinzhai culture (Zhao and Li 2003).

${ }^{1}$ Institute of Heavy Ion Physics, Peking University and Key Laboratory of Heavy Ion Physics, Ministry of Education, Beijing 100871, China.

${ }^{2}$ Corresponding author. Email: kxliu@pku.edu.cn.

${ }^{3}$ School of Archaeology and Museology, Peking University, Beijing 100871, China.

${ }^{4}$ Vienna Environmental Research Accelerator (VERA), Institut für Isotopenforschung und Kernphysik, Universitat Wien, A-1090 Wien, Austria. 
In addition to the phase belonging to the Xinzhai culture, remains belonging to the late Longshan and early Erlitou cultures were also found in the Xinzhai site. According to the analysis of the unearthed pottery ware characteristics, the Xinzhai culture can be subdivided into 2 phases: Early Xinzhai and Late Xinzhai. Therefore, the cultural remains of the Xinzhai site can be divided into 4 phases: Late Longshan, Early Xinzhai, Late Xinzhai, and Early Erlitou (Zhao and Li 2003).

\section{SAMPLE PREPARATION AND MEASUREMENT}

Contamination was very carefully avoided during sample collection and transportation. All samples selected for ${ }^{14} \mathrm{C}$ measurements are well-preserved bone samples and constitute a series that covers the archaeological phases of the Late Longshan, Early Xinzhai, and Late Xinzhai. Due to the lack of suitable dating material, samples from the Early Erlitou phase do not exist. Serial samples collected from the Erlitou site have been measured previously (Qui and Cai 2001).

Reliable dating results are obtainable when extracted gelatin is used as the dating material (Hedges et al. 1992; Wu et al. 2000). Following a standard method of sample pretreatment and preparation developed in the School of Archaeology and Museology of Peking University, the gelatin contained in the bone samples was extracted and combusted to $\mathrm{CO}_{2}$. The $\mathrm{CO}_{2}$ was then reduced to graphite (Wu et al. 2000).

The samples were measured at the upgraded PKU-AMS facility (Liu et al. 2000). The precision and accuracy of ${ }^{14} \mathrm{C}$ measurement for most samples is better than $0.5 \%$. For the purpose of quality control, most samples were measured twice, provided that there were enough dating materials. Sample pretreatment and preparation were also performed twice for the different AMS measurements of one sample. Five samples were measured at the Vienna University AMS facility (VERA) (Priller et al. 2000). For the comparison of the sample pretreatments between the 2 laboratories, gelatin extracted at Peking University and original bone materials of the same samples were sent to the Vienna University AMS laboratory.

\section{CALIBRATION}

Since the samples collected from the Xinzhai site have a good stratigraphic sequence, the Bayesian method was applied to the calibration to reduce the calendar age intervals. The program used for the calibration of ${ }^{14} \mathrm{C}$ ages was OxCal 3.9, with the calibration curve IntCa198. Samples were organized into 3 phases according to the pottery sequence. Boundaries were used at the terminals of the sequence and between the phases. If one sample had two or more ${ }^{14} \mathrm{C}$ ages, they were combined to a unique age by using the code command "combine" of OxCal 3.9.

\section{RESULTS AND DISCUSSION}

The measured ${ }^{14} \mathrm{C}$ ages and calibrated calendar ages of the samples from the Xinzhai site are shown in Table 1, and Figure 1 is the plot of the OxCal calibration. The ${ }^{14} \mathrm{C}$ ages are all in good agreement between the 2 AMS laboratories and between the 2 measurements by the PKU-AMS facility. Age differences for samples measured at VERA were pretreated separately at Vienna University and Peking University and are also within $1 \sigma$. 
Table $1{ }^{14} \mathrm{C}$ and calibrated ages of Xinzhai site samples.

\begin{tabular}{|c|c|c|c|c|}
\hline Phase & Field nr & Lab code and nr & ${ }^{14} \mathrm{C}$ age & Calendar age (BC) \\
\hline Upper boundary & & & & $2170-2040$ \\
\hline \multirow{9}{*}{ Late Longshan } & T1H123 & SA00002 & $3700 \pm 65$ & $2110-1950$ \\
\hline & T1H126 & SA00014 & $3675 \pm 35$ & $2085-2035$ \\
\hline & & SA00014-1 & $3740 \pm 30$ & \\
\hline & & VERA-1430 (gelatin) & $3760 \pm 45$ & \\
\hline & & VERA-1429a (bone) & $3695 \pm 35$ & \\
\hline & T1H122 & SA00008 & $3570 \pm 35$ & $1960-1875$ \\
\hline & T1H120 & SA00007 & $3590 \pm 30$ & $2010-1880$ \\
\hline & T1H119 & SA00001 & $3485 \pm 30$ & $1880-1840$ \\
\hline & & SA00001-1 & $3490 \pm 35$ & \\
\hline 1-2 boundary & & & & $1850-1780$ \\
\hline \multirow{9}{*}{ Early Xinzhai } & $\mathrm{T} 1(6) \mathrm{C}$ & SA00006 & $3535 \pm 35$ & $1820-1770$ \\
\hline & & SA00006-1 & $3470 \pm 35$ & \\
\hline & T1H116 & SA00012 & $3480 \pm 35$ & $1820-1765$ \\
\hline & & VERA-1432 (gelatin) & $3500 \pm 45$ & \\
\hline & & VERA-1431 (bone) & $3490 \pm 35$ & \\
\hline & T1H112 & SA00005 & $3465 \pm 35$ & $1820-1755$ \\
\hline & T1H115 & SA00019 & $3530 \pm 35$ & $1820-1770$ \\
\hline & & SA00019-1 & $3500 \pm 35$ & \\
\hline & T4H61(6) & SA00028 & $3500 \pm 35$ & $1815-1770$ \\
\hline $2-3$ boundary & & & & $1780-1745$ \\
\hline \multirow{16}{*}{ Late Xinzhai } & T1H40 & SA00018 & $3500 \pm 30$ & $1770-1740$ \\
\hline & & SA00018-1 & $3470 \pm 35$ & \\
\hline & T1H26 & SA00017 & $3395 \pm 40$ & $1750-1700$ \\
\hline & & SA00017-1 & $3455 \pm 30$ & \\
\hline & T1H76 & SA00009 & $3415 \pm 35$ & $1745-1605$ \\
\hline & T1H48 & VERA-1435 (gelatin) & $3460 \pm 50$ & $1755-1695$ \\
\hline & & VERA-1434 (bone) & $3425 \pm 35$ & \\
\hline & T1H45 & SA00013 & $3430 \pm 55$ & $1740-1710$ \\
\hline & & SA00013-1 & $3390 \pm 35$ & \\
\hline & & VERA-1437 (gelatin) & $3450 \pm 50$ & \\
\hline & & VERA-1436 (bone) & $3380 \pm 35$ & \\
\hline & T1H29(1) & SA00016 & $3410 \pm 50$ & $1745-1710$ \\
\hline & & VERA-1439 (gelatin) & $3430 \pm 50$ & \\
\hline & & VERA-1438 (bone) & $3390 \pm 35$ & \\
\hline & T4H66 & SA00021 & $3425 \pm 30$ & $1745-1705$ \\
\hline & T4H30 & SA00020 & $3490 \pm 30$ & $1775-1700$ \\
\hline Lower boundary & & & & $1730-1675$ \\
\hline
\end{tabular}




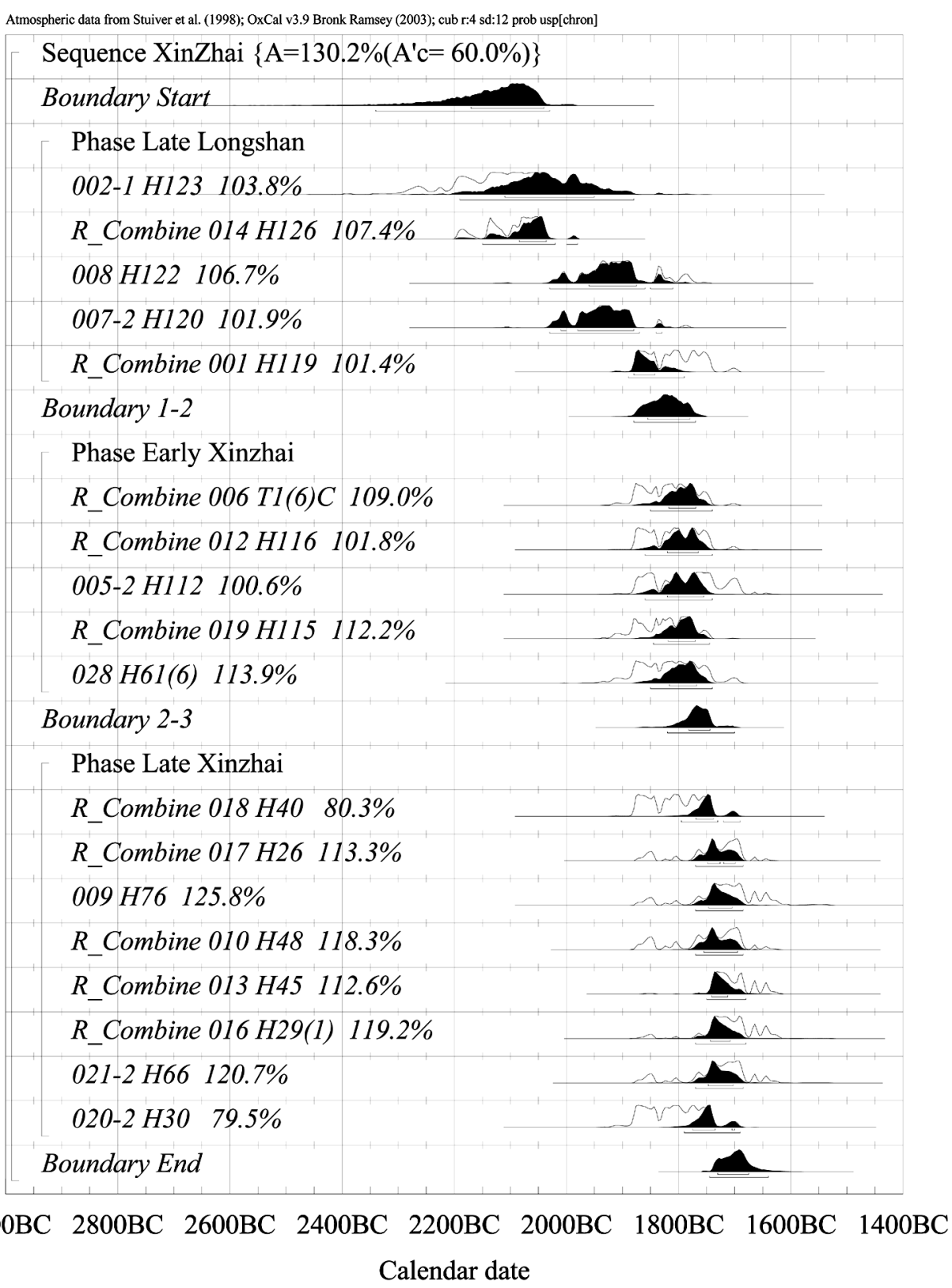

Figure 1 OxCal calibration plot of the Xinzhai site samples

${ }^{14} \mathrm{C}$ measurements of the Xinzhai site serial samples reveal preliminary chronological information about the Xinzhai culture, late Longshan culture, and early Erlitou culture, all of which are related to the Xia dynasty. According to the ages listed in Table 1, the estimated age for the transition from the Longshan culture to the Xinzhai culture is about 1840-1820 BC, and the end age of the Xinzhai culture is about $1720 \mathrm{BC}$. The Xinzhai merges with the beginning age of the Erlitou culture, which is estimated by the ${ }^{14} \mathrm{C}$ measurement of the Erlitou site serial samples. Twenty samples from the Erlitou site were collected and measured by liquid scintillation counting (LSC) at the Institute of 
Archaeology, Academy of Social Science of China -10 of them were bone and 10 were charcoal. Samples were organized into 5 phases for the calibration of ${ }^{14} \mathrm{C}$ ages and the result shows that the upper limit of the Erlitou culture is about 1780-1730 BC (Qui and Cai 2001). More samples from the Erlitou site will be measured by AMS. Given the analysis above, the Xinzhai culture should last about $120 \mathrm{yr}$.

Chinese archaeologists generally recognize that the early Erlitou culture belongs to the Xia culture. However, there are different opinions regarding the Longshan culture. Some archaeologists believe that the early Xia culture should be found in the late Longshan culture, while others claim that the Longshan culture has no relation to the Xia culture. The recent excavation and archaeological research of the Xinzhai site shows that the Xinzhai culture should belong to the Xia culture (Zhao and $\mathrm{Li} \mathrm{2003)}$ and that it is the transition culture between the Longshan and Erlitou cultures. The results of ${ }^{14} \mathrm{C}$ analysis of the Xinzhai site provide a preliminary calendar age for the Xinzhai culture that chronologically predates the Erlitou culture. These findings are important for studies regarding the origin of the Xia dynasty.

\section{ACKNOWLEDGMENTS}

We thank professor Boqian Li of the School of Archaeology and Museology, Peking University, for his helpful discussions. This work is supported by the Xia-Shang-Zhou Chronology Project.

\section{REFERENCES}

Hedges REM, van Klinken GJ. 1992. A review of current approaches in the pretreatment of bone for radiocarbon dating by AMS. Radiocarbon 34(3):279-91.

Liu K, Guo Z, Lu X, Ma H, Li B, Wang J, Zhou G, Yuan J, Ren X, Zhao Q, Zhang Z, Zhang G, Yuan S, Wu X, Li K, Chen C-E. 2000. Improvements of PKU-AMS for precision ${ }^{14} \mathrm{C}$ analysis of the Project of Xia-ShangZhou Chronology. Nuclear Instruments and Methods in Physics Research B 172:70-4

Priller A, Brandl T, Golser R, Kutschera W, Puchegger S, Rom W, Steier P, Vockenhuber C, Wallner A, Wild E. 2000. Extension of the measuring capabilities at
VERA. Nuclear Instruments and Methods in Physics Research B 172:100-6

Qiu S, Cai L. 2001. ${ }^{14} \mathrm{C}$ chronological framework in the Xia-Shang-Zhou Chronology Project. Kaogu (Archaeology) 1:90-100. In Chinese.

Wu X, Yuan S, Wang J, Guo Z, Liu K, Lu X, Ma H, Li K, Yuan J, Cai L. 2000. AMS radiocarbon dating of a cemetery of Jin marquises in China. Nuclear Instruments and Methods in Physics Research B 172:732-5.

Zhao Q, Li B. 2003. The study of Xinzhai site. Inner research report of the Xia-Shang-Zhou Chronology Project. In Chinese. 